\title{
FENOMENA PERILAKU PSIKOPAT DALAM NOVEL KATARSIS KARYA ANASTASIA AEMILIA: KAJIAN PSIKOLOGI SASTRA
}

\section{Reza Rozali ${ }^{\bowtie}$, Mulyono, Maharani Intan Andalas IRP}

Jurusan Bahasa dan Sastra Indonesia, Fakultas Bahasa dan Seni, universitas Negeri Semarang, Indonesia

\begin{abstract}
Info Artikel
Sejarah Artikel:

Diterima April 2016

Disetujui Juli 2018

Dipublikasikan

November 2018

Keywords:

psychopaths, psychopathic

behavior phenomena,

literary psychology

Abstrak

Kasus kriminalitas di Indonesia beberapa tahun terakhir menunjukkan peningkatan yang begitu memprihatinkan, serta pada beberapa kasus dikaitkan dengan gangguan gejala psikopat. Psikopat ialah bentuk kekalutan mental yang ditandai dengan tidak adanya pengorganisasian dan pengintegrasian pribadi, tidak bisa bertanggung jawab secara moral, selalu konflik dengan norma sosial dan hukum yang diciptakkan oleh angan-angannya sendiri. Penelitian ini bertujuan untuk mendeskripsikan fenomena perilaku psikopat pada novel Katarsis karya Anastasia Aemilia dengan pendekatan psikologi sastra, khususnya menggunakan teori gangguan kepribadian psikopat Sigmund Freud. Pada dasarnya psikologi sastra memberikan perhatian pada masalah kejiwaan para tokoh fiksional yang terkandung dalam karya sastra. Sasaran dalam penelitian ini adalah fenomena perilaku psikopat yang dialami oleh tokoh dengan mengkaji bentuk perilaku, dan faktor penyebabnya. Teknik analisis data yang digunakan adalah teknik deskriptif kualitatif. Berdasarkan hasil penelitian dapat diketahui bahwa (1) bentuk perilaku psikopat tokoh dalam novel Katarsis karya Anastasia Aemilia diketahui berdasarkan ciri perilaku khusus pada psikopat yaitu berperilaku antisoasial, suka memanipulasi, berperilaku agresif, berperilaku sadistis, serta tidak menyesal dan tidak merasa bersalah sehingga dapat ditentukan bentuk perilaku psikopat yang terbagi ke dalam tiga bentuk, yaitu ringan, sedang, dan berat. (2) Faktor yang menyebabkan tokoh dalam novel Katarsis berperilaku psikopat yaitu faktor biologis dan faktor lingkungan.
\end{abstract}

Abstract

Cases of criminality in Indonesia in recent years have shown such an alarming increase, and in some cases linked to psychopathic symptoms disorder. Psychopaths are forms of mental disorder that is characterized by lack of organization and personal integration, can not be morally responsible, always conflict with social norms and laws created by wishful thinking alone. This study aims to describe the phenomenon of psychopathic behavior in the novel Katarsis by Anastasia Aemilia with the approach of literature psychology, in particular using the theory of psychopath personality disorder from Sigmund Freud. Basically, literature psychology gives attention to the psychological problems of the fictional characters contained in the literary work. Target in this research is phenomenon of psychopathic behavior experienced by the character by studying the form of behavior, and the cause factor. Data analysis technique used is descriptive qualitative technique. Based on the results of the research can be seen that (1) the form of psychopathic behavior of characters in the novel Katarsis by Anastasia Aemilia is known based on specific behavior on the psychopath that is behaving antisoasial, like to manipulate, behave aggressively, behave sadistis, and not regret and not feel guilty, so it can be determined form psychopathic behavior is divided into three forms, a light, medium, and heavy. (2) Factors that cause characters in the novel Katarsis behave psychopaths namely biological factors and environmental factors.

(C) 2018 Universitas Negeri Semarang

\footnotetext{
Alamat korespondensi:

Gedung B1 Lantai 1 FBS Unnes

Kampus Sekaran, Gunungpati, Semarang, 50229

E-mail: vusufsvaifulamin@gmail.com
}

ISSN 2252-6315 


\section{PENDAHULUAN}

Fenomena perilaku psikopat yang terjadi di masyarakat secara tak sadar telah mengilhami berbagai bentuk karya seni salah satunya karya sastra. Hal itu terjadi karena karya sastra tak lepas dari pengarang yang menciptakanya. Fenomena perilaku psikopat itu oleh pengarang dituangkan berdasarkan pengalamannya yang berkaitan dengan psikopat atau imajinasi pengarang yang mampu menggambarkan tokoh seorang psikopat. Psikopat secara etimologis merupakan gabungan kata dari bahasa Yunani yaitu psyche dan pathos yang berarti penyakit jiwa. Psikopat berbeda dengan gila (psikosis), karena seorang psikopat sadar sepenuhnya atas perbuatannya. Gejala psikopat sendiri disebut dengan psikopati (Aksan 2008:65).

Menurut Freud (dalam Sarwono 2009:266) psikopat adalah orang yang ego-nya terlalu dikuasai oleh id dan superego tidak ada wibawa atau pengaruh sama sekali terhadap ego. Jadi ego hanya mendengarkan apa kata $i d$, yang artinya semua tindakan seorang psikopat didasari oleh keinginan id semata, tanpa memperdulikan baik-buruk tindakan tersebut.

Salah satu jenis dari karya sastra adalah prosa, khususnya novel, merupakan potret kehidupan manusia yang tersaji dalam cerita panjang. Novel juga dapat dijadikan bahan untuk mempelajari sifat manusia. Berbagai macam sifat manusia dan fenomena hidup tercermin dalam sebuah novel termasuk fenomena prilaku psikopat.

Psikopat menjadi menarik untuk dijadikan tema dalam sebuah karya sastra karena ceritanya yang menguras emosi dan mengaduk-aduk psikologi pembaca. Psikologi sendiri secara umum diartikan sebagai ilmu yang mempelajari kepribadian serta gejala-gejala kejiwaan. Psikologi adalah ilmu pengetahuan yang mempelajari semua tingkah laku dan perbuatan individu, dimana individu tersebut tidak dapat dilepaskan dari lingkunganya (Fauzi 1999:13).

Jatman (1985:165) berpendapat bahwa karya sastra dan psikologi memang memiliki hubungan yang erat, secara tak langsung dan fungsional. Hubungan tak langsung yang dimaksudkan adalah baik sastra maupun psikologi kebetulan memiliki tempat berangkat yang sama, yaitu kejiwaan manusia. Sedangkan hubungan fungsional antara sastra dan psikologi adalah keduanya sama-sama berguna sebagai sarana untuk mempelajari keadaan kejiwaan orang lain. Perbedaannya adalah dalam karya sastra gejala-gejala kejiwaan dari manusia-masia imajiner sebagai tokoh dalam karya sastra, sedangkan dalam psikologi adalah gejala kejiwaan manusia-manusia riil.

Tema psikopat juga menjadi menarik untuk diteliti karena tidak adanya perbedaan secara jelas antara seorang psikopat dengan manusia berkepribadian normal lainnya. Dalam penelitian karya sastra, fenomena perilaku psikopat masuk dalam kajian psikologi sastra, karena pada dasarnya psikologi sastra memberikan perhatian pada masalah kejiwaan para tokoh fiksional yang terkandung dalam karya sastra (Ratna 2002:343).

Dari sekian banyak karya sastra yang menampilkan fenomena perilaku psikopat, penelitian ini menggunakan novel yang berjudul Katarsis karya Anastasia Aemilia sebagai objek penelitian. Katarsis adalah novel pertama Anastasia yang terbit pada tahun 2013. Katarsis mengangkat sebuah kisah psyhcology thriller dengan psikopat sebagai persoalan utamanya. Novel ini secara jelas menampilkan fenomena perilaku psikopat berupa siksaan, kekerasan, bahkan pembunuhan yang dilakukan oleh tokoh yang ada di novel tersebut.

Novel Katarsis karya Anastasia Aemilia, memperlihatkan dengan jelas bahwa tokoh psikopat pada novel ini tidak segan untuk membunuh siapa pun yang berurusan dengannya tanpa ada rasa penyesalan, bahkan kepada yang tak bersalah sekalipun. Oleh tindakan yang keji itulah Katarsis penuh dengan fenomena perilaku psikopat yang direfleksikan melalui tokoh-tokohnya. Fenomena-fenomena perilaku yang dilakukan oleh tokoh psikopat tersebut yang menarik untuk diteliti dan menjadi sasaran penelitian ini.

Pada sebuah penelitian diperlukan adanya kajian pustaka. Kajian pustaka berfungsi untuk memberikan pemaparan tentang penelitian dan analisis sebelumnya yang telah dilakukan. Penelitan yang dapat dijadikan acuan, bandingan, serta tolak ukur untuk penelitian ini adalah penelitian yang dilakukan oleh Caroline Logan (2011), Samuel J. Leistedt dan Paul Linkowski (2013), Anak Agung Dewi Wulan Sari (2015), Regin Yohan Syawamaredo Gotama (2015), dan Sinduk Farhanatul Fauziyah (2016).

Novel Katarsis pernah diteliti pada aspek konflik dan kepribadian oleh Anak Agung Dewi Wulan Sari yaitu pada skripsi Universitas Udayana yang berjudul "Analisis Psikologi Sastra Novel Katarsis karya Anastasia Aemilia" (2015). Hasil penelitian tersebut menunjukkan bahwa pada novel Katarsis kepribadian tokoh primer mengalami gangguan kepribadian antisosial (psikopat). Sari juga membagi tahapan dalam 
menganalisis kepribadian tokoh primer menjadi tiga tahapan yaitu, tahapan kepribadian awal, tahapan kepribadian psikopat, dan tahapan kepribadian mengalami katarsis. Pada penelitian Sari, menganalisis struktur merupakan langkah kerja awal sebelum menganalisis aspek kepribadian tokoh. Kemudian penelitian Sari menggunakan teori psikologi dalam menganalisis psikologi sastra pada novel Katarsis ini, yaitu gangguan kepribadian antisosial.

Berbeda dengan penelitian sebelumnya, penelitian ini akan mengungkap fenomena perilaku psikopat berdasarkan tokoh yang terdapat pada novel Katarsis dengan teori psikologi sastra, khususnya teori psikopat menurut Sigmund Freud. Perbedaan lainnya, penelitian ini akan membahas bentuk perilaku psikopat, serta faktor yang menyebabkan tokoh dalam novel Katarsis mengalami gangguan kepribadian psikopat.

Selain kajian pustaka juga dipaparkan mengenai teori yang mendukung pembahasan sebagai landasan pokok dalam pengkajian. Teori yang digunakan dalam skripsi ini, yaitu (1) hakikat novel, (2) novel-novel psikologis, (3) teori psikologi sastra, (4) teori psikologi kepribadian, (5) teori psikologi kepribadian Sigmund Freud, dan (6) teori gangguan kepribadian psikopat yang berisi ciri-ciri psikopat, dan faktor penyebab psikopat.

\section{METODE PENELITIAN}

Sasaran atau objek yang dikaji dalam penelitian ini adalah fenomena perilaku psikopat yang dialami oleh tokoh dalam novel Katarsis karya Anastasia Aemilia. Secara lebih khusus, penelitian ini mengkaji bentuk perilaku berdasarkan ciri-ciri, dan faktor penyebab dari perilaku psikopat yang dilakukan oleh tokoh dalam novel Katarsis karya Anastasia Aemilia. Pendekatan yang digunakan dalam penelitian ini adalah pendekatan kualitatif deskriptif.

Data yang dijadikan objek penelitian adalah data yang berupa kata, kalimat, dan wacana pada novel Katarsis karya Anastasia Aemilia yang memuat bentuk perilaku, ciri-ciri, dan faktor penyebab dari perilaku psikopat yang terjadi pada tokoh. Teknik pengumpulan data dalam penelitian ini menggunakan kajian studi pustaka, kemudian data dalam penelitian ini dianalisis untuk mencari bentuk perilaku dan faktor yang menyebabkan tokoh berperilaku psikopat dalam novel Katarsis karya Anastasia Aemilia.

\section{HASIL PENELITIAN DAN PEMBAHASAN}

Penelitian terhadap novel Katarsis ini menggunakan teori psikologi sastra, secara lebih khusus menggunakan teori gangguan kepribadian Sigmund Freud. Pertama, peneliti menganalisis bentuk dari perilaku psikopat yaitu perilaku psikopat tokoh berdasarkan pada ciri-ciri. Kedua, peneliti menganalisis faktor yang menyebabkan tokoh dalam novel Katarsis berperilaku psikopat.

\section{Bentuk Perilaku Psikopat pada Tokoh dalam Novel Katarsis Karya Anastasia Aemilia}

Peneliti menggunakan ciri-ciri psikopat yang dikemukakan Hermawan Aksan (2008:6667), dan alat ukur Psychopath Check List - Revised (PCL-R) Hare (dalam Purwanto, 2015:4) untuk membuktikan bahwa tokoh dalam novel Katarsis berperilaku psikopat, selanjutnya peneliti menganalisis perilaku tokoh berdasarkan ciri-ciri psikopat, sehingga dapat menentukan bentuk perilaku pada ketiga tokoh dalam novel Katarsis.

Berdasarkan ciri-ciri psikopat yang telah disebutkan pada landasan teoretis, peneliti menggolongkan ciri-ciri tersebut ke dalam beberapa perilaku psikopat, karena ciri-ciri psikopat tersebut membangun perilaku khusus yang dilakukan oleh seorang psikopat. Perilaku khusus itu antara lain; (1) berperilaku antisosial, (2) suka memanipulasi, (3) berperilaku agresif, (4) berperilaku sadistis, dan (5) tidak menyesal dan merasa bersalah.

\section{a. Berperilaku Antisosial}

Perilaku antisosial pada seorang psikopat terjadi karena kurangnya kemampuan memproses informasi secara emosional, dan kurangnya kemampuan dalam memahami orang lain. Perilaku antisosial pada novel Katarsis terjadi pada tokoh Tara yaitu, ketika Tara tidak menunjukan kepedulian pada pernikahan ayahnya, berperilaku acuh terhadap keluarga Arif Johandi, tidak menunjukkan tanggung jawabnya terhadap Bara telah membunuh Tari, dan lebih mementingkan dirinya sendiri, tanpa berpikir bagaimana perasaan Bara setelah kematian Tari. Pada tokoh Ello ketika ia tidak bisa merasakan sakit pada tubuhnya sendiri dan menggantinya dengan mencari rasa sakit kepada orang lain.

\section{b. Suka Memanipulasi}

Perilaku suka memanipulasi merupakan ciri yang sering dilakukan oleh seorang psikopat untuk melancarkan atau menutupi aksi kejahatannya. Dalam pelaksanannya, bentuk perilaku suka memanipulasi ini dilakukan oleh psikopat dengan cara berbohong, menipu, dan 
memanfaatkan korbanya, baik secara verbal atau nonverbal.

Perilaku suka memanipulasi dalam novel Katarsis ditunjukan pada tokoh Tara yaitu ketika Tara bungkam dimintai keterangan oleh polisi atas kasus pembunuhan berantai di Bandung, dan tidak mengaku kepada Alfons tentang apa yang telah dirinya lakukan terhadap keluarganya. Suka memanipulasi pada tokoh Ello yaitu ketika ia mendengarkan cerita masalalu Tara, dan ketika mengingkari janjinya kepada Tara. Suka memanipulasi pada tokoh Heru yaitu ketika ia berbohong kepada Ello bahwa ia tidak melakukan apapun pada kelurga Tara.

\section{c. Berperilaku Agresif}

Perilaku agresif pada seorang psikopat biasanya lebih dari perilaku agresif pada kebanyakan orang, seorang psikopat bisa saja tidak puas dengan serangan fisik atau verbal mereka biasanya akan puas ketika membunuh telah korbanya. Hal itu terjadi karena seorang psikopat memiliki emosi yang dangkal, mudah terpancing karena hal sepele, dan tidak dapat mengendalikan diri (impulsif).

Perilaku agresif dalam novel Katarsis terjadi pada tokoh Tara yaitu, ketika Tara menyerang Moses dengan gesper, ketika Ello meneror Alfons karena rasa cemburu, yaitu ketika Tara membunuh Sasi dengan pisau dapur, dan ketika Ello menyiksa dan membunuh seorang wanita di sebuah apartemen.

\section{d. Berperilaku Sadistis}

Sadistis merupakan perilaku seseorang yang memiliki kecenderungan menyakiti orang lain dengan kejam. Perilaku ini merupakan bentuk dari cara psikopat memperlakukan korbannya seperti menyiksa, membunuh, bahkan mutilasi. Semua tindakan yang mereka lakukan hanya berdasar kepada keinginan semata dan tanpa perasaan (empati). Seorang psikopat, memotong kepala ayam dan memotong kepala manusia tidak ada bedanya, sebab seorang psikopat biasanya kurang dan bahkan tidak memiliki sifat empati itu.

Perilaku sadistis karena kurang empati dalam novel Katarsis pada tokoh Tara yaitu ketika tokoh Tara tidak menunjukan empati saat membunuh seorang anak dan ibu di taman, dan tak menunjukan empati membunuh Moses. Berperilaku sadistis pada tokoh Ello yaitu ketika ia tidak menunjukan empati saat membunuh Alfons. Berperilaku sadistis pada tokoh Heru yaitu ketika ia tidak menunjukan empati saat membunuh korbanya termasuk adiknya sendiri.

\section{e. Tidak Menyesal dan Tidak Merasa Bersalah}

Perilaku tidak menyesal dan tidak merasa bersalah pada seorang psikopat muncul karena ketidakmampuan superego pada seseorang untuk menekan keinginan id, sehingga ego membenarkan keinginan dari id meskipun kenginan itu berupa menganiaya bahkan sampai membunuh sekalipun.

Perilaku tidak menyesal dan tidak merasa bersalah dalam novel Katarsis terjadi pada tokoh Tara yaitu ketika Tara tak merasa bersalah telah membunuh seorang anak dan ibu ditaman, ibunya sendiri, Moses, dan Sasi. Tidak menyesal dan merasa bersalah pada tokoh Ello ketika ia tidak merasa bersalah dan menyesal telah membunuh seorang wanita di apartemen dan membunuh Alfons.

Berdasarkan pemaparan analisis perilaku psikopat di atas, disimpulkan bahwa bentuk perilaku psikopat pada tokoh dalam novel Katarsis karya Anastasia Aemilia dibagi menjadi tiga bentuk perilaku yaitu, bentuk perilaku psikopat ringan, bentuk perilaku psikopat sedang, dan bentuk perilaku psikopat berat. (1) Bentuk perilaku psikopat ringan, yaitu perilaku seorang psikopat yang secara umum menyimpang dari norma-norma sosial, seperti; berperilaku antisoasial dan suka memanipulasi. (2) Bentuk perilaku psikopat sedang yaitu perilaku seorang psikopat yang secara umum menyimpang dari hukum. Psikopat sedang mengandalkan kekerasan tanpa disertai pembunuhan seperti; berperilaku agresif tanpa membunuh. (3) Bentuk perilaku psikopat berat yaitu perilaku seorang psikopat yang secara umum menyimpang dari norma sosial, hukum, bahkan agama. Psikopat berat mengandalkan kekerasan dengan disertai pembunuhan seperti agresif disertai membunuh, berperilaku sadistis, dan tidak menyesal dan merasa bersalah.

\section{Faktor-Faktor Penyebab Tokoh Berperilaku Psikopat dalam Novel Katarsis Karya Anastasia Aemilia}

Menurut Aksan (2008:65-66), faktor yang menyebabkan seorang menjadi psikopat disebabkan oleh faktor biologis, lingkungan, dan traumatis.

\section{a. Faktor Biologis}

Faktor penyebab tokoh berperilaku psikopat secara biologis disebabkan kelainan genetis, dan adanya perubahan pada psikis kimiawi tubuh seperti ketakutan, rasa cemas, dan frustasi pada seseorang. Rasa itu muncul karena 
adanya kegagalan dalam struktur kepribadian super-ego, pada kasus seorang psikopat, superego gagal dalam mengawasi atau menekan keinginan sempurna dari keinginan id yang di dominasi oleh ego.

Tokoh yang berperilaku psikopat karena faktor biologis pada novel Katarsis, yaitu tokoh Ello. Hal itu disebabkan Ello mengidap congenital insensitivity to pain atau ketidakmampuan merasakan rasa sakit. Congenital insensitivity to pain adalah kelainan genetik yang disebabkan oleh mutasi pada gen $S C N 9 A$ dan, dalam kasus yang jarang terjadi disebabkan oleh mutasi pada gen PMRD12.

\section{b. Faktor Lingkungan}

Faktor penyebab tokoh berperilaku psikopat secara lingkungan disebabkan oleh pengaruh lingkungan di mana seseorang tumbuh dan dibesarkan. Pengaruh tersebut meliputinorma dalam keluarga, teman, kelompok sosial, dan pengaruh-pengaruh lain yang seorang dapat alami.

Tokoh yang berperilaku psikopat karena faktor lingkungan pada novel Katarsis, yaitu tokoh Tara. Hal itu disebabkan oleh lingkungan keluarganya yang keras, terutama Bara, ayahnya. Tara tak pernah mau dipanggil dengan nama 'Tara' oleh kedua orangtuanya, namun orangtua Tara tetap memanggilnya dengan nama itu sehingga membuatnya tertekan. Oleh karena hal tersebut Tara mengalami tekanan dari lingkungan kelurganya, hingga Tara berperilaku membunuh.

\section{c. Faktor Traumatis}

Kata traumatis memiliki arti keadaan jiwa terguncang oleh suatu peristiwa di masa lalu. Peristiwa tersebut mempengaruhi psikis seseorang yang menimbulkan trauma atau prespektif lain yang berlainan dengan norma-norma atau aturan yang ada di masyarakat.

Dalam novel Katarsis tidak ditemukan adanya tokoh yang keadaan jiwanya terguncang oleh suatu peristiwa di masa lalu. Tidak ditemukan pula kutipan yang menunjukkan peristiwa traumatis yang dialami tokoh dan mengakibatkannya menjadi seorang psikopat, sehingga faktor penyebab tokoh berperilaku psikopat dalam novel Katarsis, hanya berupa faktor biologis yang terjadi pada tokoh Ello dan faktor lingkungan yang terjadi pada tokoh Tara.

\section{PENUTUP}

Berdasarkan hasil penelitian dapat diketahui bahwa (1) bentuk perilaku psikopat yang dialami tokoh Tara, Ello dan Heru dalam novel Katarsis karya Anastasia Aemilia terbagi ke dalam tiga bentuk yaitu; ringan, sedang dan berat. Bentuk perilaku psikopat tersebut diketahui berdasarkan perilaku khusus pada seorang psikopat yaitu perilaku antisoasial, suka memanipulasi, berperilaku agresif, berperilaku sadistis, dan tidak menyesal dan tidak merasa bersalah. (2) Faktor yang menyebabkan tokoh dalam novel Katarsis berperilaku psikopat yaitu faktor biologis, dan faktor lingkungan. Faktor biologis dalam novel Katarsis terjadi pada tokoh Ello, ia mengidap congenital insensitivity to pain atau ketidakmampuan merasakan rasa sakit. Faktor lingkungan dalam novel Katarsis terjadi pada tokoh Tara yang disebabkan oleh lingkungan keluarganya.

Berdasarkan hasil penelitian, diharapkan penelitian ini dapat menjadi referensi bagi pembaca untuk menghasilkan karya-karya baru, berupa caranya maupun medianya terutama yang menggunakan teori psikologi sastra dan gangguan kepribadian psikopat. Perlu diadakan penelitian lanjutan yang lebih mendalam dengan kajian yang berbeda karena penelitian ini hanya berpusat pada fenomena perilaku psikopat berupa bentuk perilaku dan faktor penyebabnya. Masih banyak aspek lain yang belum pernah dikaji untuk menambahkan wawasan atau pengetahuan kita.

\section{DAFTAR PUSTAKA}

Aemilia, Anastasia. 2013. Katarsis. Jakarta. PT. Gramedia Pustaka Utama.

Aksan, Hermawan. 2008. Jejak Pembunuh Berantai: Kasus-Kasus Pembunuhan Berantai Di Indonesia dan Dunia. Jakarta Timur: PT. Grafindo Media Pratama

Jatman, Darmanto. 1985. Sastra, Psikologi, dan Masyarakat. Bandung: Penerbit Alumni.

Endraswara, Suwardi. 2008. Metode Penelitian Psikologi Sastra. Teori, langkah, dan Penerapanya. Yogyakarta: Med Press.

Fauzi, Ahmad. 1999. Psikologi Umum. Bandung: Pustaka Setia.

Fauziah, Sinduk Farhanatul. 2016. Tokoh Psikopat dalam Novel Straw Karya Noorca Marendra Massardi: Analisis Psikoanalisis Sigmund Freud. Skripsi. Universitas Gadjah Mada. Yogyakarta.

Gotama, Regin Yohan Syawamaredo. 2015. Analisis Perilaku Psikopatik Tokoh Utama dalam Dongeng La Barbe Bleue Karya Charles Perrault. Skripsi. Universitas Brawijaya. Malang.

Leistedt, Samuel J. dan Paul Linkowski. 2013. "Psychopathy and the Cinema: Fact or 
Fiction?". Jurnal of Forensic Sciences. Vol 15. Hlm, 167-174. Amerika. American Academy of Forensic Sciences.

Logan, Caroline. 2011. "La Femme Fatale: The Female Psychopath in Fiction and Clinical Practice". Mental Health Review Jurnal. Vol 16. Hlm, 118-127. Inggris: Emerald Group Publishing Limited.

Ratna, Nyoman Khuta. 2012. Teori, Metode, dan Teknik Penelitian Sastra. Yogyakarta: Pustaka Pelajar.

Sari, Anak Agung Dewi Wulan. 2015. Analisis Psikologi Sastra Novel Katarsis karya Anastasia Aemilia. Skripsi. Universitas Udayana. Bali.

Sarwono, Sarlito W. 2009. Pengantar Psikologi Umum. Jakarta: PT. Raja Grafindo Persada. 